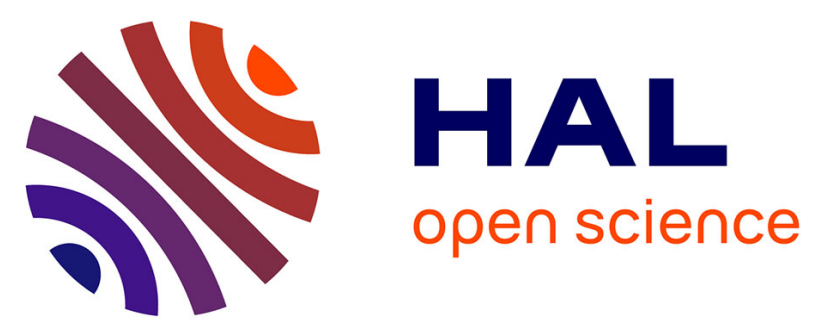

\title{
Improving the Innovation Process by Harnessing the Usage of Content Management Tools Coupled with Visualization Tools
}

\author{
Houcine Dammak, Mickaël Gardoni
}

\section{To cite this version:}

Houcine Dammak, Mickaël Gardoni. Improving the Innovation Process by Harnessing the Usage of Content Management Tools Coupled with Visualization Tools. 15th IFIP International Conference on Product Lifecycle Management (PLM), Jul 2018, Turin, Italy. pp.642-655, 10.1007/978-3-030-016142_59. hal-02075556

\author{
HAL Id: hal-02075556 \\ https://hal.inria.fr/hal-02075556
}

Submitted on 21 Mar 2019

HAL is a multi-disciplinary open access archive for the deposit and dissemination of scientific research documents, whether they are published or not. The documents may come from teaching and research institutions in France or abroad, or from public or private research centers.
L'archive ouverte pluridisciplinaire $\mathbf{H A L}$, est destinée au dépôt et à la diffusion de documents scientifiques de niveau recherche, publiés ou non, émanant des établissements d'enseignement et de recherche français ou étrangers, des laboratoires publics ou privés. 


\title{
Improving the innovation process by harnessing the usage of content management tools coupled with visualization tools
}

\author{
Houcine Dammak ${ }^{1}$, Mickaël Gardoni ${ }^{1,2}$ \\ ${ }^{1}$ École de technologie Supérieure, Montréal, Canada \\ ${ }^{2}$ Institut National des Sciences Appliquées, Strasbourg, France \\ Houcine.dammak.1@ens.etsmtl.ca \\ Mickael.gardoni@etsmtl.ca
}

Keywords: Content Management, Big Data, Innovation Process, Ideation, Creativity, Knowledge Management, Graph, Visualization.

\begin{abstract}
.
Having an intelligent and a creative workplace in which employees, machines and stakeholders are more productive by accessing easily to the information and making better decisions is becoming one of the main areas that organizations are investing in nowadays in order to stay competitive in the market.

Today, organizations have access to multiple information that contains valuable data from internal and external sources. These information are present everywhere in the workplace and represent a huge amount of data. Content Management tools appeared to manage this huge amount of information. It was proved that Big Data has a contribution to creativity, the next step would be to show how Content Management solutions could be used to improve innovation process.

We believe that using Big Data and Content Management tools will make a positive difference in the first steps of the innovation process, that is to say the creativity/ideation part. We will be also coupling Content Management tools and visualization tools to support our approach. Indeed, having a framework that integrates these tools, Big Data, Content Management and visualization tools, in the day to day, should improve the workplace innovation process to make it more "intelligent" and "creative".
\end{abstract}

\section{Introduction}

The majority of organizations today are investing in having an intelligent and creative work-place. These investment decisions are due to multiple changes that are affecting the market. The main changes are the new technologies and its important advancement that increased the competition and made it global and also the apparition of small players that disrupted the market and are presenting a threat to organizations that are not following the wave of technology. Recent studies show that corporate life expectancy is decreasing. Professor Richard N. Foster shows in a study published by Innosight that corporate life expectancy was 61-year tenure in 1958 then decreased to 
25 years in 1980 and to 18 years in 2012. This study is based on the S\&P 500 index (Standard \& Poor's) [1].

The market is changing rapidly and every organization is trying to do its best to stay alive. They should follow an agile methodology in their offer in order to be flexible with the market. Many organizations like Kodak, Nokia, Blockbusters and Blackberry for example disappeared or are struggling because they did not innovate in their products and offerings. Other companies, they are excelling very well and innovating every day like Apple that did a successful shift in its offer to follow the new technologies. Innovation may differ from one company to another and it is not necessarily related to the product. It may be related to a process, a market... The question that every each executive should ask is: Do I want my organization to be Apple or Black berry?

So, how those organizations will be able to innovate?

Many people may think that by implementing an innovation program they will become innovative. They will capture ideas and then evaluate them but not necessarily those ideas are with high added value. And usually the ideation step is one the most critical step in an innovation process. The ideation step require the access to valuable information. The majority of the existing methodologies encourage organizations to collect ideas from employees, suppliers, clients... Those insights have shown interesting added value in many organization due to the proactive behavior that is developed with stakeholders. The fact that organizations today have access to multiple information from different sources, this may led to a competitive ad-vantage. Availability of information is one of the critical success factors for organizations to survive. While trying to overcome this critical success factor, organizations are facing different challenges like the huge volume of data and information that exist in different formats and that is not easy to use. So, organizations today are facing a significant amount of uncontrolled content that needs to be managed efficiently.

To cope with this challenge, Content Management Tools appeared. Content Management tools has different names but the most common one is ECM (Enterprise Content Management). It is defined as the technologies, tools, and methods used to capture, manage, store, preserve, and deliver content across an enterprise (AIIM) [2]. It is also defined as a collection of strategic resources and capabilities that provides an automated enabling framework for efficient lifecycle management of valuable organization asset, i.e. contents and processes, to carry out required business operations in a collaborative fashion, supports governance and compliance, provides integration within and outside the business boundaries to achieve business intelligence, knowledge management and decision support capabilities with focus on fulfillment of business goals and objectives for competitive advantage [3].

In the literature, we find that the majority of researchers focused on the operational and tactical benefits of ECM and very few of them focused on the strategic benefits. From the operational benefits, using ECM will allow saving costs and reducing workload by streamlining tasks, and improving search and retrieval [4]. Concerning the tactical benefits, ECM improves internal and external collaboration, enhances content quality and maintain consistency and standardizes workflows. From a strategic level, it includes increasing decision making capabilities and facilitating creativity [4]. 
In this work, we are exploring different ways to add other layers to the innovation program like the use of Content Management tools in a way that helps us to optimize this process. We are proposing a framework showing how Content Management tools could be beneficial in the ideation step of an innovation process.

\section{Problem Statement}

The ideation step in an innovation process is a critical step. Providing tools to participants in ideation sessions may enhance the creativity. As mentioned above, ECM is a tool that will be provided to participants of ideation sessions in order to see its impact on the creativity of an organization. ECM users will have access to valuable information that are structured and easily accessible. This access to information will allow to enhance the creativity of users to create new knowledge. The gap is present and the benefits expected are really promising but unfortunately until today, in the ECM research, Creativity, Innovation and Knowledge Management has played a minor role.

With the Content Management tool, we are planning to use indexes (Metadata) related to each content in order to do searches. By using this metadata layer, the participant will receive a list of contents as a search result. The majority of commercial ECM tools present the search results as a list of contents (documents) grouped by the category of the content (Example: Thesis, Article, Product Catalog, Invoices...) and details with all the metadata related (Date, field, author, location, university...). The metadata depends on the category of documents and it is configured at the implementation stage of an ECM solution. So, the participants of an ideation session, depending on the criteria that they will select, will receive a list of content as a search results. This list of content may inspire them in their ideation session to come up with innovative ideas.

Here is a presentation of the use of content management tools in an innovation process:

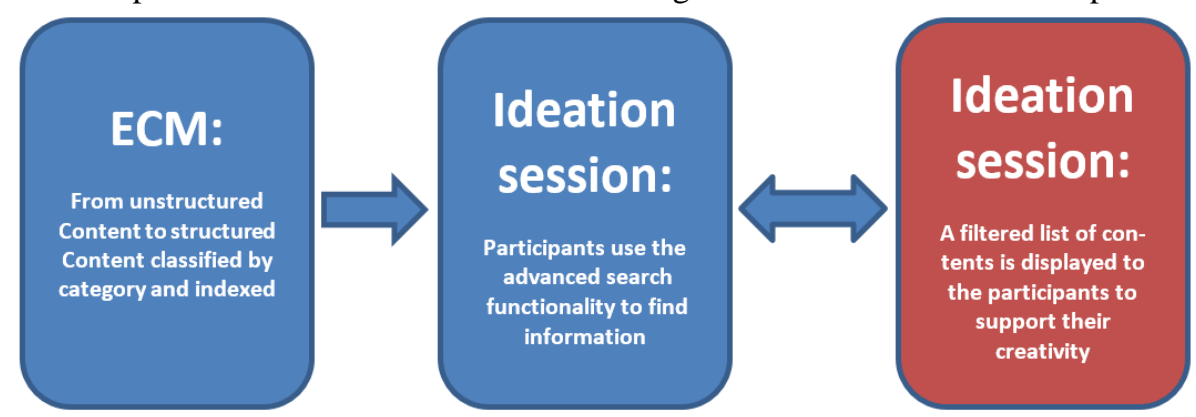

Figure 1: Modelling the use of Content Management tools in an innovation process

As a result, the search result is presented as a list of contents grouped by category. But within a specific category we don't have any grouping, the only information is the content name, description and all the metadata related.

Some researchers proved that access to large database of information can overwhelm users, in their innovation process, and tend them to return to known solutions which will decrease the creativity. To avoid this situation, instead of presenting the search 
results to participants as a list of contents with the metadata related, we will be proposing a relational analysis between these contents in order to display them in a graph which may help them.

In this context, we are planning to explore the use of content management tools to support the creativity. As mentioned previously, ECM is the platform that stores content and make it available to users when then need it. So, we will be proposing a framework that couples the ECM output and the innovation process at the ideation stage. And this by proposing a relational analysis of the list of contents displayed by the ECM and representing them in a graph. The difficulty here is about the important number of analysis properties to identify the right graphs and all the combinations between these analysis properties.

So, this work will focus on identifying the most pertinent graphs from all the possible set of graphs that will allow to exploit content management tools in the innovation process.

\section{How the use of Content Management tools coupled with visualization tools support} the ideation step in the innovation process?

\section{State of the art}

\subsection{The Innovation Process}

With new technologies and the ease of access to information, organizations today need to innovate continuously. Different approaches are used to manage the Innovation program and the majority of the existing methodologies encourage organizations to collect ideas from employees, suppliers, clients... Those insights have shown interesting added value in many organization due to the proactive behavior that is developed with stakeholders. In this section, we will present the Innovation system as described by Robert George Cooper and Scott J. Edgett [5].

The authors state that many companies have already a solid innovation process or a Stage-Gate system implemented. So the process is in place to launch new product or process. This Stage-Gate system starts from Stage 1: ideas to Stage 5: Launch. Senior executives considers that the process is not enough if we don't have the right input which is strong and high value ideas. 


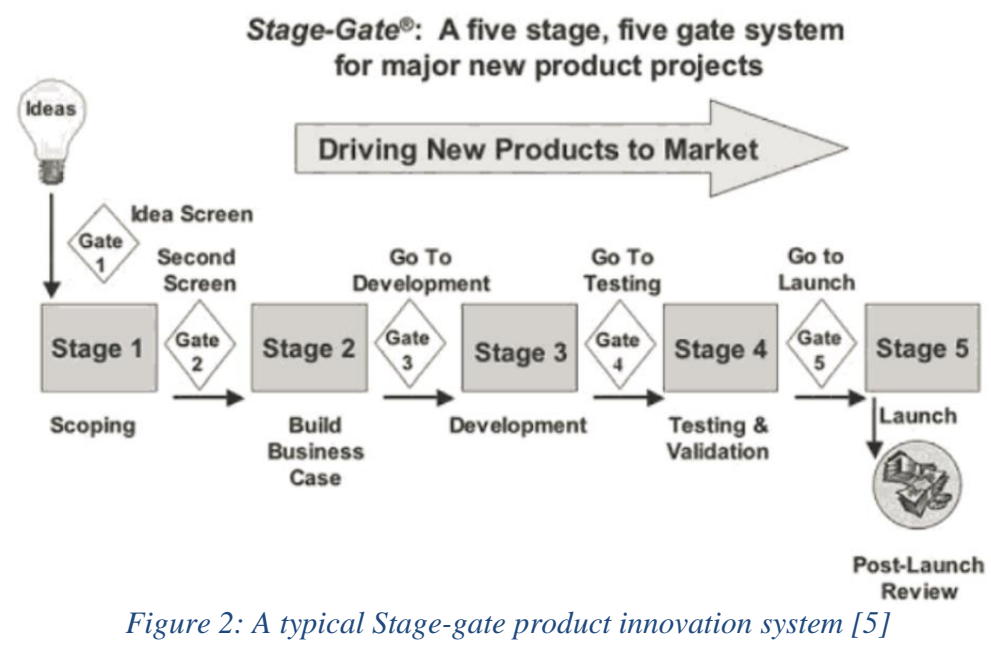

Different approaches appeared to solve this problem like organizing: Brainstorming sessions, Jam sessions, Innovation days, challenge-driven events, Shark Tank competitions... and these events proved their results by providing a huge number of ideas and then following an evaluation process we could reach the expected strong and high value ideas.

The ideation process which is the first step in the innovation process is the most critical step. We believe that companies can leverage their knowledge throughout the organization, expand their knowledge further based on existing expertise, appropriate knowledge from partners and other organizations, and develop completely new expertise by probing new technologies or markets [6].

Some authors propose that to generate radical innovations, it is necessary to combine al-ready existing knowledge but in an unexpected fashion [7].

The combination of teams existing technical knowledge and limited domain-specific knowledge provokes more original and diverse ideas, which confirms there is creative value in the combination of KDD (knowledge discovery from databases) with teams' existing knowledge [8].

So, existing knowledge is very important for the ideation step. This existing knowledge may come from internal or external data that an organization holds or has access to. In the following section, we will present the importance of data in this context and researchers positioned it in the innovation process.

\subsection{Importance of Data}

For all organizations regardless their size, their market or their market share, they all have to deal with data in different forms. This data represents a valuable source of knowledge. We start here by defining some key terms that will be used in this work.

- Data: Are symbols that represent the properties of objects and events [9].

- BIG Data: the volume of the data is too large. Secondly, it is impossible to analyze it using conventional technologies [10]. 
- Knowledge: Can be defined as information that is validated, contextual, relevant and actionable [11]. Jacob \& al [12] defined it as a massive pool of data that allows creating in-sights and values that are not possible to generate from smaller scale of same data.

- Tacit Knowledge: is subjective and informal [13] [14]. It is usually hard to express, transfer or share using common ways.

The data that any organization has comes from different sources and in different forms. Ka-bir and Carayannis [15] present knowledge into two forms: Explicit and Tacit. It is usually impossible to analyse it using conventional technologies especially if we add to this data the information available on the internet. That's why and as mentioned above, it called Big Data.

Several researchers studied the importance of Big Data and the knowledge that it has for organizations.

Provost and Fawcett [16] mention that insights and knowledge from big data boost management's ability to take well-informed decisions.

According to Kabir and Carayannis [15], knowledge has all the potential of creating economic value for an organization and bolster innovation, productivity and growth. Thus, it is also a possible major source of competitive advantage.

Knowledge and the capability to create and utilize knowledge are considered to be the most important source of a firm's sustainable competitive advantage [16] [14] [17].

In a nutshell, Big data:

- Is a source of innovation that can enable development of new products, processes and services.

- Using various analytics data can generate knowledge and insights that can support and improve organizational decision making significantly [18].

- Offers the promise of unlocking novel insights and accelerating breakthroughs [19].

\subsection{Content Management Tools}

As mentioned previously, access to digital data is becoming much easier and cheaper that's why we believe that Big Data will make a huge difference in the quality of innovation in an organization. Some researchers have already worked on this and proved that Big Data may result a positive impact on the generated ideas [8].

Today, organizations has a huge amount of data from different sources. These data is in dif-ferent formats: documents, management platforms, databases... that is not easy to use and that represent a huge amount of uncontrolled content that needs to be managed efficiently. Content management tools has appeared to cope with these challenges. Content Management tools could become the system of record of all these data and knowledge.

Enterprise Content Management (ECM) has been defined as "the strategies, tools, processes, and skills an organization needs to manage all its information assets (regardless of type) over their lifecycle" [20]. 
ECM is different from other management platforms. It manages the entirely of an organization's assets like: reports, spreadsheets, web pages, presentations, emails, office documents, images, audio or video files... [21]. Figure 3 models the ECM system.

\section{efficiency, availability, traceability, and consistency}

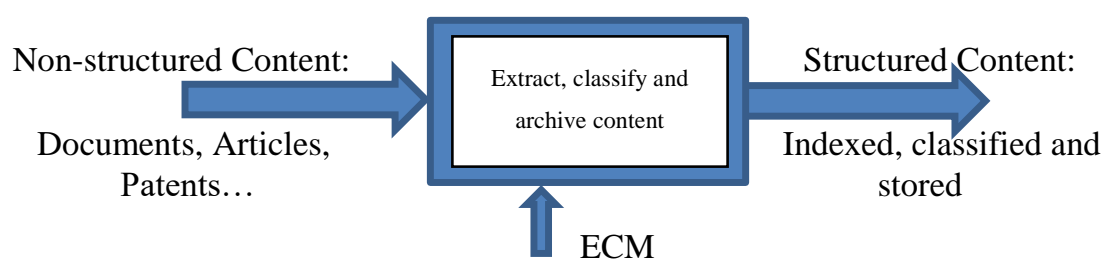

Figure 3: Modelling the ECM system

An ECM implementation should follow the following content stewardship activities presented in the following figure [14]:

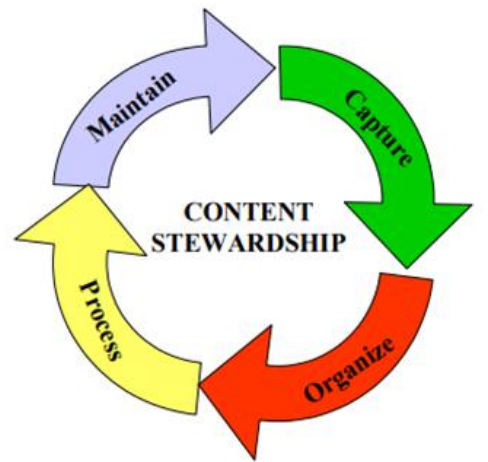

Figure 4: Content Stewardship are at the heart of an ECM strategy [14]

- Capture: It contains all the activities related with collecting content. It is usually about identifying the content that it wants to capture and all its dimensions. This content could be captured from internal to external databases.

- Organize: It involves indexing, classifying and linking databases together. This step utilize different techniques like: OCR (Optical Character Recognition) and smart templates for indexing, workflows for classification based on business rules and ODBC connections to link content with other databases.

- Process: Analyze the content already classified in order inform decision makers and other existing management systems.

- Maintain: It is mainly related to the maintenance of the content. How to keep it accessible? How to link it with new content? And for how much time we should keep it? 
ECM solutions are mainly used for daily and operational tasks. Usually, the main reasons to implement ECMs are: reducing searching times, unifying the presentation or adhering to reporting obligations [21].

After organizing and structuring the content, ECM will deliver it to users in the format of a list. We will be using visualization tools to change this output to a graph format that highlights the relationships between contents.

\section{Methodology}

Content management tools could support the innovation process in different stages. In this work, we are considering the Content Management tool as a system of record for all the company's content. Users of this tool will be provided access to all the company's content in one single location linked to all other existing management platforms. This may reduce search times and access to information will be easier. Then, we will be exploring how this tool could support the innovation process at the ideation stage.

As mentioned above, we will be working on the output of the ECM, which is a list of contents structured and classified, to represent it in a graph and provide it to participants in an ideation session. So, we will see the impact of using a graph of contents versus not using it at the ideation stage. The evaluation of the ideas will be done by an independent evaluation team who will rank the ideas.

Here is a presentation of the use of content management tools coupled with visualization tools:

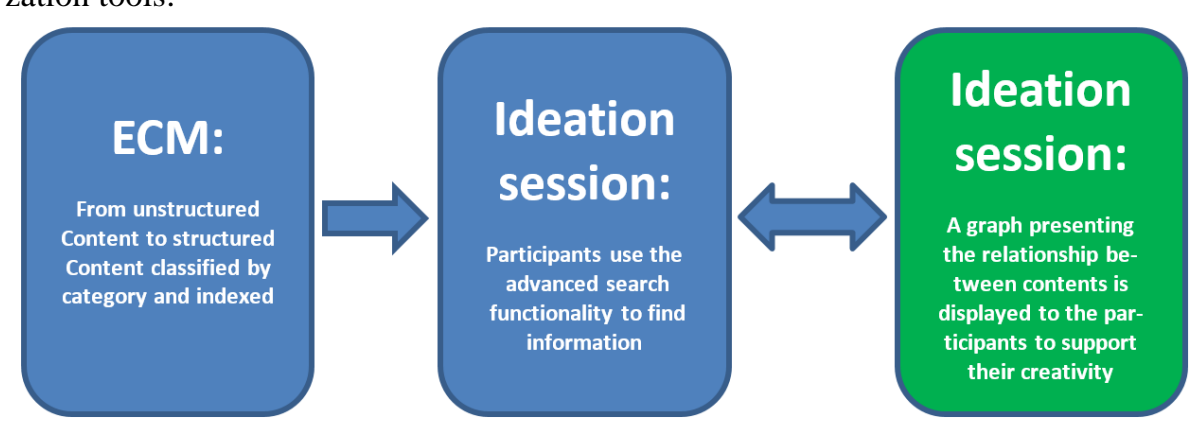

Figure 5: ECM coupled with visualization tools in an innovation process

Using a visualization tool will present a second layer of filtering content - To group them together based on certain parameters. The search result will be presented in a Graph with links and weights. So, we are propose a relational analysis of the list of contents displayed by the ECM and representing them in a graph. The difficulty here is about the important number of analysis properties to identify the right graphs and all the combinations between these analysis properties.

Here is an example showing a list of contents (search result). This example considers that we have two categories of contents (the first one is Thesis) and the first category has three indexes (University, Field and Year). 
Table 1. Contents stored within the example and related indexes

\begin{tabular}{|c|c|c|c|c|c|c|c|c|c|}
\hline & & & & \multicolumn{3}{|c|}{ Category 1} & \multicolumn{3}{|c|}{ Category 2} \\
\hline & & & & index & index & index & index & index & index \\
\hline category & & & & University (a) & Field (b) & Year (c) & d & $\mathrm{e}$ & $\mathrm{f}$ \\
\hline 1 & Content & $\mathrm{c} 1$ & Thesis 1 & ETS (x) & Innovation (s) & $2012(\mathrm{u})$ & & & \\
\hline 1 & Content & c2 & Thesis 2 & McGill (y) & Innovation (s) & $2012(\mathrm{u})$ & & & \\
\hline 1 & Content & c3 & Thesis 3 & Concordia (z) & Innovation (s) & $2012(\mathrm{u})$ & & & \\
\hline 1 & Content & c4 & Thesis 4 & ETS (x) & Innovation (s) & $2012(\mathrm{u})$ & & & \\
\hline 1 & Content & c5 & Thesis 5 & ETS (x) & Innovation (s) & 2015 (j) & & & \\
\hline 1 & Content & c6 & Thesis 6 & ETS (x) & Electrical (r) & 2015 (j) & & & \\
\hline 1 & Content & c7 & Thesis 7 & McGill (y) & Electrical (r) & $2012(\mathrm{u})$ & & & \\
\hline 1 & Content & c8 & Thesis 8 & Concordia (z) & Electrical (r) & 2012 (u) & & & \\
\hline 2 & Content & c9 & & & & & $q$ & $\mathrm{t}$ & p \\
\hline 2 & Content & $\mathrm{c} 10$ & & & & & $q$ & $\mathrm{t}$ & $\mathrm{p}$ \\
\hline 2 & Content & c11 & & & & & $q$ & $\mathrm{t}$ & p \\
\hline 2 & Content & $\mathrm{c} 12$ & & & & & $q$ & $\mathrm{t}$ & p \\
\hline 2 & Content & c13 & & & & & w & $\mathrm{i}$ & 1 \\
\hline 2 & Content & c14 & & & & & w & o & 1 \\
\hline 2 & Content & $\mathrm{c} 15$ & & & & & w & o & 1 \\
\hline 2 & Content & c16 & & & & & $q$ & o & $\mathrm{k}$ \\
\hline
\end{tabular}

The goal here is to study the links between all the contents presented in the search result and to present them in a graph. To do this, we need to present the Content/Index matrix and then the Content/Content Matrix.

Once we present the Content/ Content matrix, a graph presenting the links between contents based on indexes can be presented. Different graphs tools are available.

In this example, we can consider the indexes to link the contents. Different other parameters could be considered and also different graphs are possible to draw. So, this work is focusing on identifying the most pertinent graphs from all the possible set of graphs that will allow to exploit content management tools in the innovation process.

The range of possible graphs is wide and depends on different parameters. Some researchers already did the exercise of analyzing the different software tools (software) [25] and found their number is important and in general, the overall architecture of these software tools is structured according to a reference model provided by Card [26]. This reference model will be used as a guideline to our methodology.

Card [26] presents visualization (graph) as a mapping from data to a visual form that the human perceives. The following figure presents this reference model that shows how the flow of data goes through a series of transformations. The human may interfere at different steps to make adjustments to these transformations. 


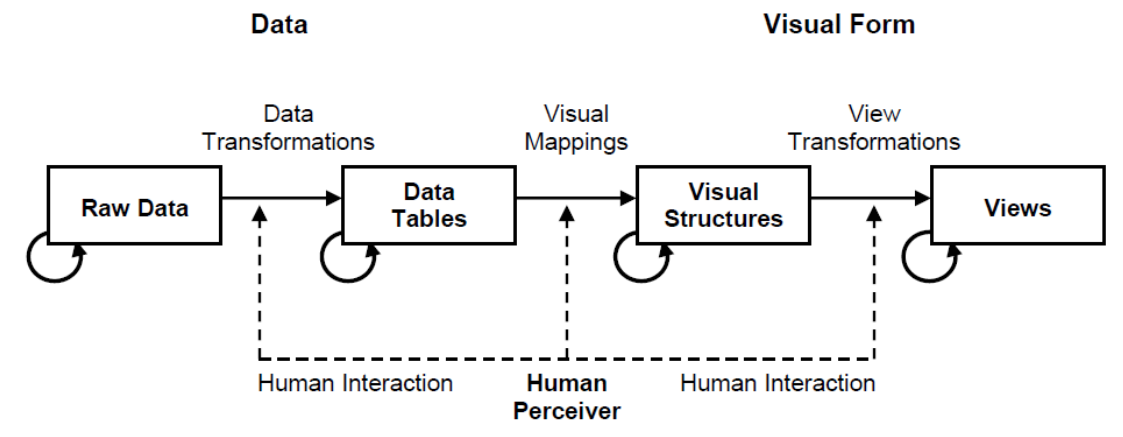

Figure 6: Reference Model for Visualization [26]

Using an analogy to this reference model to apply it in our context, the following figure presents the modelling of our methodology that will be explained later step by step:

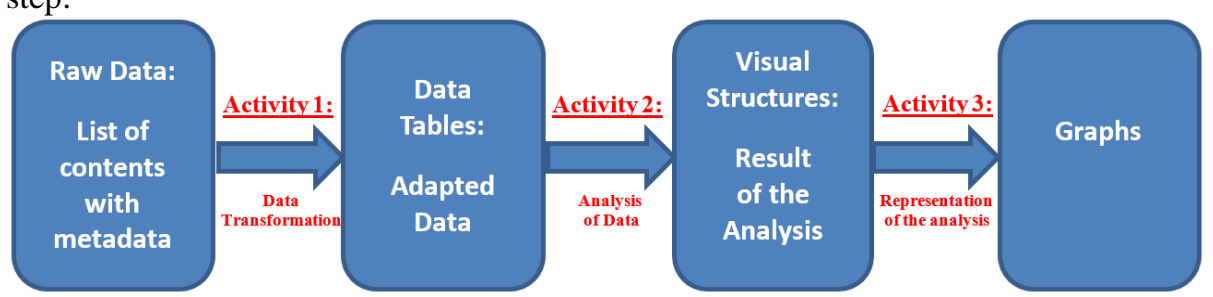

Figure 7: Methodology to convert the output of the ECM to a Graph

- Activity 1:

As mentioned above, the output of the ECM is considered our input in the innovation process. In our methodology, it is considered as raw data. Activity 1 which is data transformation converts raw data into more usable data tables. In our context, the raw data is a list of contents with metadata and is difficult to use by participants in ideation sessions since it could overwhelm them and have negative impact on their creativity. This activity will transform the list of contents to an adapted state of data which is easier to analyze. The adapted data is usually presented in a table format and shows the relationship between data. The example that we presented above is a sample of data transformation.

\section{- Activity 2:}

This activity will analyze the adapted data and present its result in different format. The core of the reference model is the mapping of adapted data to results of the analysis. Data tables are based on mathematical relationships whereas the results of the analysis are based on graphical properties processed by human vision. In the reference model, this is the most difficult activity. To manage it, we are planning to follow these steps: 
- Contextual filter:

From the adapted data, we have different data in tables. Different analysis properties are possible to analyze the relationship between contents. In this step, we are planning to enumerate them based on the literature then doing a contextual filter related the context of ECM and innovation process. So, we identify what are the properties that could be applied and that make sense to use them.

\section{- Statistical verification:}

Once we identify the most pertinent properties that applies to our context, we will validate them by doing tests on small sample. We are planning to do the tests with patents. So, uploading them to the ECM, extracting metadata, analyzing the relationship between them and displaying the most appropriate graph then using those graphs in small brainstorming session at the research lab level.

From this activity, we are able to analyze all the relationship between contents and identifying the most important analysis properties.

- Activity 3:

The aim of this activity is to transform the result of the analysis to graphs. It is about representing in a comprehensive way to users.

Once we converted the output of the ECM to graph, we are planning make this approach available to participants of ideation sessions. We will be testing this approach in an industrial environment and in the $24 \mathrm{~h}$ Innovation event organized by ETS. Then, we will be comparing the impact of proving of graphical tool representing the contents to participants versus not using it and presenting to users to list of contents in a list format.

So, we will be using an independent evaluation team to evaluate the ideas from both approaches (with the graphical tool and without) to observe its impact on the creativity.

Actually, for the coming edition of $24 \mathrm{~h}$ innovation that will be held at ÉTS, we will be testing the following scenario:

1- We will identify a complex challenge that requires a lot of reading (in the $24 \mathrm{~h}$ event, challenges are submitted by businesses)

2- From the teams that will participate in this challenge, we will selected 2 teams. We will try to find two similar teams (background, age, gender percentage, ...)

3- The first team will have access to an ECM that has already thousands of contents (documents) uploaded into it and indexed. The team will use the advanced search functionality to search for relevant fields. A list of contents will be displayed depending on their search criteria and then they have to consult each one of them to get inspiration.

4- The second team will have access to the same ECM as team one with the same content. While doing their search for relevant content, instead of displaying the search result as a list of content, it will be displayed as a graph grouping 
contents depending on certain parameters and relating them with links. Then, participants will consult those contents.

5- Once the 24 hour is over, both teams will submit their solutions to the jury in a 2 min video (this is the current format used in the $24 \mathrm{~h}$ event). Then, a local and international jury will evaluate the proposed solutions (ideas) and rank them.

6- Depending on the ranking giving by the independent jury, we will assess the results to see if there is an impact of providing a graph to users while they are doing their ideation session.

7- This scenario will be tested with at least 10 teams and 5 challenges so at least statistically we can confirm the obtained results.

Once we confirm the expected results with the $24 \mathrm{~h}$ event, we will do the same scenario in an industrial environment.

\section{Conclusion}

The amount of content and information is increasing every day in a very fast pace. And organization has to look to this amount as an opportunity and use it in their innovation process in order to become more creative. In this work, we presented a framework on how content management tools coupled with visualization tools may participate in the innovation process within an organization.

The purpose of using content management tools is to benefit from the huge amount of in-formation which is considered as a wealth of knowledge. As explained, the content itself is present in different sources and it is unstructured but with using the proposed tools, we will be able to structure this content and use it in the innovation process.

The next work is expected to test the different approaches presented in this paper and to discuss the obtained results.

\section{References:}

1. https://www.innosight.com/wp-content/uploads/2016/08/creative-destruction-whips-through-corporate-america_final2015.pdf

2. AIIM: Association for Information and Image Management. www.aiim.org

3. Usman, M., Muzaffar, A.W. and Rauf, A., 2009, August. Enterprise Content Management (ECM): needs, challenges and recommendations. In Computer Science and Information Technology, 2009. ICCSIT 2009. 2nd IEEE International Conference on (pp. 283-289). IEEE. https://doi.org/10.1109/ICCSIT.2009.5234541

4. Alalwan, J.A., Thomas, M.A. and Weistroffer, H.R., 2014. Decision support capabilities of enterprise content management systems: An empirical investigation. Decision Support Systems, 68, pp.39-48. https://doi.org/10.1016/j.dss.2014.09.002

5. Cooper, R.G. and Edgett, S.J., 2009. Generating breakthrough new product ideas: Feeding the innovation funnel. Product Development Institute.

6. Von Krogh, G., Nonaka, I. and Aben, M., 2001. Making the most of your company's knowledge: a strategic framework. Long range planning, 34(4), pp.421-439. https://doi.org/10.1016/S00246301(01)00059-0 
7. Fleming, L. and Szigety, M., 2006. Exploring the tail of creativity: an evolutionary model of breakthrough invention. In Ecology and Strategy (pp. 335-359). Emerald Group Publishing Limited.

8. Escandon-Quintanilla, M.L., 2017. Effects of data exploration and use of data mining tools to extract knowledge from databases (KDD) in early stages of the Engineering design process (EDP) (Doctoral dissertation, École de technologie supérieure).

9. Ackoff, R.L., 1989. From data to wisdom. Journal of applied systems analysis, 16(1), pp.3-9.

10. Manyika, J., Chui, M., Brown, B., Bughin, J., Dobbs, R., Roxburgh, C. and Byers, A.H., 2011. Big data: The next frontier for innovation, competition, and productivity.

11. Soliman, F. and Youssef, M., 2003. The role of critical information in enterprise knowledge management. Industrial Management \& Data Systems, 103(7), pp.484-490.

12. Jacobs, A., 2009. The pathologies of big data. Communications of the ACM, 52(8), pp.36-44.

13. Polanyi, M., 1958. Personal knowledge: Toward a Post-critical Philosohy, University of Chicago, IL.

14. Nonaka, I., 1991. The Knowledge-Creating Company Harvard Business Review November-December, pp.96-104.

15. Kabir, N. and Carayannis, E., 2013, January. Big data, tacit knowledge and organizational competitiveness. In Proceedings of the 10th International Conference on Intellectual Capital, Knowledge Management and Organisational Learning: ICICKM (p. 220).

16. Nonaka, I., 1990. Chishiki-Souzou no Keiei (A theory of organizational knowledge creation). Nihon Keizai Shimbun-sha: Tokyo (in Japanese).

17. Nonaka, I., Byosiere, P., Borucki, C.C. and Konno, N., 1994. Organizational knowledge creation theory: a first comprehensive test. International Business Review, 3(4), pp.337-351.

18. Provost, F. and Fawcett, T., 2013. Data science and its relationship to big data and data-driven decision making. Big Data, 1(1), pp.51-59.

19. Chen, Y., Argentinis, J.E. and Weber, G., 2016. IBM Watson: how cognitive computing can be applied to big data challenges in life sciences research. Clinical therapeutics, 38(4), pp.688-701.

20. Smith, H.A. and McKeen, J.D., 2003. Developments in practice VIII: Enterprise content management. The Communications of the Association for Information Systems, 11(1), p.41.

21. Vom Brocke, J., Seidel, S. and Simons, A., 2010, January. Bridging the gap between enterprise content management and creativity: A research framework. In System Sciences (HICSS), 2010 43rd Hawaii International Conference on (pp. 1-10). IEEE.

22. Deo, N., 2017. Graph theory with applications to engineering and computer science. Courier Dover Publications.

23. Gregory, R.L., 2000. L'oeil et le cerveau: la psychologie de la vision. De Boeck Supérieur.

24. Bertin, J., 1981. Graphics and graphic information processing. Walter de Gruyter.

25. Dkhil, A., 2011. Identification systématique de structures visuelles de flux physique de production (Doctoral dissertation, Strasbourg).

26. Card, S.K., Mackinlay, J.D. and Shneiderman, B. eds., 1999. Readings in information visualization: using vision to think. Morgan Kaufmann. 